\title{
Some Aspects of Immune Status of Primary and Secondary Schoolchildren Living in Conditions of Technogenic Pollution of Urban Environment by Industrial Pollutants
}

\author{
K.G. Starkova ${ }^{1}$ and O.V. Dolgikh,"* \\ ${ }^{I}$ Department of immunobiological diagnostic methods, Federal Scientific Center for Medical and Preventive Health \\ Risk Management Technologies, Perm, Russia \\ ${ }^{*}$ Corresponding author. Email: oleg@fcrisk.ru
}

\begin{abstract}
Under conditions of intensive industrial impact, the study of the specifics of the regulatory systems response will benefit effective implementation of measures aimed to preserve the health of the child population. We have studied the indicators of the immune status of schoolchildren at different levels of education under the industrial impact of the urban environment. CD-populations of lymphocytes have been studied by flow cytometry. Humoral immunity has been assessed based on the production of serum immunoglobulins by radial immunodiffusion, and specific antibodies to chemical factors - by allergosorbent testing. It has been revealed that the immune profile imbalance is especially pronounced in middle school students and is characterised by the following: a decrease in CD19 ${ }^{+}$and $\mathrm{CD}^{+}$ lymphocytes, a reduced phagocytic activity, an increase in $\operatorname{IgM}$ and IgA production, a high level of sensitization for specific IgE to manganese, nickel, formaldehyde, IgG to lead, benzene, phenol, changes in the cytokine markers of interleukin-4 and interferon-gamma. These indicators reflect the state of immunological health of schoolchildren and serve as indicators of the formation of pathological trends in the context of industrial changes of the environment, which can be used for early detection of immune-mediated morbidity and development of effective preventive measures to improve the quality of life and provide a decrease in the incidence rate of children.
\end{abstract}

Keywords: immune status, primary and secondary schoolchildren, technogenic pollution, urban environment, industrial impact, regulatory systems response

\section{INTRODUCTION}

The scale of technogenic impact on the environment is constantly increasing, the problem of the quality of living conditions is especially important in industrially developed regions where constant monitoring of both the state of the environment and the influence of the external environment on the health of the population with regards to the impact specifics and the peculiarities of the adaptive reserve of the regulatory systems of the body including immune protection is required [1-5].

Preserving the health of the younger generation in conditions of intensive industrial exposure is possible through the implementation of complex measures regarding the age characteristics of schoolchildren and based on the development of prognostic criteria for the functional state of the immune regulation system aimed to ensure early detection of immune-mediated morbidity and improve the effectiveness of treatment and prophylactic measures [6-8].

Violation of the harmonious physiological development of children and adolescents is associated with an unfavorable combination of technogenic chemical, physical and socio-economic factors, which under conditions of increased stress loads form the insufficiency of regulatory systems for ensuring homeostasis and serve as a prerequisite for the 
development of immune-mediated diseases. The immune system reacts to environmental factors by functional shifts of both the cellular and humoral defense links, which, as a result of excessive loads, can contribute to the formation of disorders with pathological changes in the state of health, the identification of which at early stages will provide a decrease in the incidence rate of the child population in conditions of unfavorable changes in the environment [9-11].

The purpose of the study is to determine the peculiarities of changes in the parameters of immune regulation in primary and secondary schoolchildren living in areas with an intensive level of industrial exposure.

\section{MATERIALS AND METHODS}

Schoolchildren living in a large industrial center with a developed industrial infrastructure were involved in the study. The state of health of children of the $1^{\text {st }}$ grade (observation group No.1 comprising 48 children with an average age of $7.36 \pm 0.07$ years) and $6^{\text {th }}$ grade children (observation group No. 2 comprising 27 children with an average age of $12.81 \pm 0.13$ years) was studied. The comparison groups consisted of schoolchildren of the $1^{\text {st }}$ grade (comparison group No.1 children with an average age of $7.58 \pm 0.10$ years) and $6^{\text {th }}$ grade (comparison group No.2 comprising 35 children with an average age of $12.47 \pm 0.10$ years) studying at a general education institution of the regional center with no large industrial enterprises. All groups were comparable in terms of age, gender, presence of somatic diseases $(\mathrm{p}>0.05)$.

All legal representatives of the children signed the informed consents to participate in the study. The work was carried out in accordance with the Declaration of Helsinki and approved by the Ethics Committee of the Federal Scientific Research Center for Medical and Preventive Technologies for Managing Public Health Risks.

The content of metals (manganese, nickel, and lead) in biological media of children was determined on an Agilent 7500cx mass spectrometer (Agilent Technologies Inc., USA) by the inductively coupled plasma method in accordance with the organization's standards and guidelines. The level of organic compounds (benzene, phenol) was investigated by gas chromatography on a gas chromatograph with a flame ionization detector Kristall 5000 (Russia); formaldehyde was studied on an Agilent 1200 chromatograph by high performance liquid chromatography.

To assess the immune status of schoolchildren, cell parameters were studied using membrane CD markers; lymphocyte fractions were determined on a FACSCalibur flow cytometer (Becton Dickinson, USA) using the universal CellQuest.PrO program; panels of labeled monoclonal antibodies were used, and at least 10000 events were recorded in total. Phagocytic activity was studied using formalized sheep erythrocytes as objects of phagocytosis. Serum immunoglobulins IgA, $\mathrm{IgM}, \mathrm{IgG}$ were determined by the method of radial immunodiffusion according to Mancini, and the content of total IgE, interleukin-4, interferon-gamma - on the analyzer Elx808IU (BioTek, USA) by enzyme immunoassay. To identify specific IgE antibodies to manganese, nickel, formaldehyde, IgG to lead, benzene, phenol, we used allergosorbent testing with an enzyme label.

The performed chemical-analytical and immunological studies were carried out on certified equipment according to standard methods in accredited laboratories of the Federal Scientific Research Center for Medical and Preventive Technologies for Managing Public Health Risks.

Statistical analysis of the data was performed using the Statistica 6.0 software package (Statsoft, USA); arithmetic mean (M) and standard error of the mean (m) were calculated. The significance of intergroup differences was assessed by the Student's t-test; the differences were considered significant at $\mathrm{p}<0.05$.

\section{RESULTS}

According to the results of chemical analysis (Table 1), schoolchildren of observation group No. 1 permanently residing in conditions of intense industrial exposure showed high concentrations of chemicals in the blood, exceeding the background levels established for the region (Perm region of Russia) in $62.2 \%$ of children for nickel, $47.6 \%$ for benzene, $97.8 \%$ formaldehyde $(\mathrm{p}=0.000-0.001)$. For observation group No.2, a significant excess of the background level was also shown for nickel, benzene, formaldehyde in $88.9 \%, 46.2 \%, 100 \%$ of children, respectively ( $\mathrm{p}=0.000-0.006)$.

Immunodiagnostic examination of children showed pronounced changes in cellular parameters, production of immunoglobulins and specific sensitization of schoolchildren in the observation group (Table 2). The features of the $\mathrm{CD}$ immunogram did not significantly differ from the physiological level. However, for the observation group No. 2, there was predominantly 1.47 times decrease in $\mathrm{CD}_{1} 9^{+}$cells relative to the comparison group ( $\mathrm{p}=0.016)$, as well as 1.15 times increase in the number of $\mathrm{CD}^{+}$lymphocytes $(\mathrm{p}=0.049$, the differences are reliable in terms of the frequency excess of the norm). Depressing effects in the observation group No.2 were noted for the fraction of $\mathrm{CD}^{+}$lymphocytes, on average by 1.33 times, while a significant shift of 1.36 times in the $\mathrm{CD}^{+} / \mathrm{CD}^{+}$parameter was shown $(\mathrm{p}=0.001-0.03)$. 
When assessing phagocytic activity, no deviation of indicators from the physiological norm was revealed, however, a decrease in the level of phagocytosis by the value of relative phagocytosis and phagocytic number in the observation group No. 2 relative to the comparison group was shown by 12 and $14 \%$, respectively $(\mathrm{p}=0.001-0.003)$.

The levels of serum immunoglobulins of classes A, $\mathrm{M}$ and $\mathrm{G}$ in the examined schoolchildren corresponded to the age norm, at the same time, a $16.4 \% \mathrm{IgG}$ overproduction was revealed in the observation group No.1 relative to the comparison group No.1 $(\mathrm{p}=0.000)$ and $\operatorname{IgM}(\mathrm{p}=0.044$, the differences are significant by the multiplicity of norm exceedance). The schoolchildren of the observation group No.2 also showed a tendency to the activated production of immunoglobulins with a significant value according to the IgM criterion $(\mathrm{p}=0.043$, the differences are significant in the multiplicity of norm exceedance) and $\operatorname{IgA}(\mathrm{p}=0.018)$ by 8.8 and $22.9 \%$, respectively, relative to the comparison group No.2. When comparing the indicators of schoolchildren at different levels of education, there was revealed an excess of $\operatorname{IgM}$ and $\operatorname{IgA}$ levels in the observation group No.2 by 1.2 and 1.31 times, respectively $(\mathrm{p}=0.001-0.006)$.

At the same time, in the observation group No.2, an increase in the level of general sensitization according to the IgE criterion was noted in 2.65 times relative to the comparison group No. 2, and also 2.71 times relative to the observation group No.1 $(\mathrm{p}=0.047-0.049)$. An increase in the level of specific immunoglobulins $\operatorname{IgG}$ to benzene, phenol, lead in comparison with the reference values was shown in 70.8-88.9\% of children in the observation groups $(\mathrm{p}=0.000)$. In addition, the content of specific $\operatorname{IgE}$ antibodies to manganese, nickel, formaldehyde, IgG to lead, benzene, phenol in the observation group No.1 exceeded the indices of the comparison group by 7.7, 8.4, 9.7, 4.8, 5.1 and 6.7 times, respectively $(\mathrm{p}=0.000)$. In the observation group No.2, an increase in these indicators was also noted by $5.3,10.6,12.1,4.8,6.9,6.0$ times, respectively $(\mathrm{p}=0.000)$.
Analysis of the cytokine regulation mechanism indicated multidirectional trends in the production of regulatory markers associated with an average 3.39 times increase in the level of interleukin- 4 significant in the observation group No. 1 relative to the comparison group, and inhibition of interferon-gamma in the observation group No.1 by 2.22 times and in the observation group No. 2 by 2.15 times $(\mathrm{p}=0.000)$. When comparing the indicators of the observation groups No. 1 and No. 2, a significant decrease in the level of interleukin-10 was noted on average by 1.51 times $(\mathrm{p}=0.000)$.

The study indicates significant changes in the immune system of schoolchildren in living conditions with a high industrial load, and for students of the middle stage of education, more significant changes in immune reactivity are characteristic, which indicates the significant importance of both the specificity of the external environment and the duration of exposure, and the age characteristics of children [12, 13]. Numerous scientific works confirm the relevance of studying the characteristics of the response of the immune regulation system in conditions of unfavorable environmental influences among different age groups of the population, children are especially sensitive to changes in living conditions, which is associated with imperfect adaptive mechanisms and, with an increased contaminant load, can determine the formation of a high level of morbidity in areas of ecological trouble [14-16]. The changes in the immune status of middle school students revealed in this work reflect not only functional shifts in immunocompetent cells associated with hyperproduction of immunoglobulins, but also a shift in the balance of cell subpopulations. Especially noteworthy is the high level of specific sensitization of pupils and, in general, changes in the humoral component of the immune adaptation mechanism for an effective response and preventive measures to improve the quality of life and preserve the health of the child population.

Table 1. The content of contaminants in the blood of the examined schoolchildren under industrial impact $(\mathrm{M} \pm \mathrm{m})$

\begin{tabular}{|l|l|l|l|}
\hline Indicator & Background level & Observation group No.1 & Observation group No.2 \\
\hline Manganese, $\mu \mathrm{g} / \mathrm{cm}^{3}$ & $0.013 \pm 0.004$ & $0.011 \pm 0.001$ & $0.012 \pm 0.002$ \\
\hline Nickel, $\mu \mathrm{g} / \mathrm{cm}^{3}$ & $0.0022 \pm 0.002$ & $0.0053 \pm 0.00164 \mathrm{a}$ & $0.0064 \pm 0.00223 \mathrm{a}$ \\
\hline Lead, $\mu \mathrm{g} / \mathrm{cm}^{3}$ & $0.0144 \pm 0.067$ & $0.0111 \pm 0.00139$ & $0.0117 \pm 0.00202$ \\
\hline Formaldehyde, $\mu \mathrm{g} / \mathrm{cm}^{3}$ & $0.005 \pm 0.0076$ & $0.035 \pm 0.00537 \mathrm{a}$ & $0.0343 \pm 0.00427 \mathrm{a}$ \\
\hline Benzene, $\mu \mathrm{g} / \mathrm{cm}^{3}$ & $0.0 \pm 0.0$ & $0.00028 \pm 0.00015 \mathrm{a}$ & $0.00023 \pm 0.00017 \mathrm{a}$ \\
\hline Phenol, $\mu \mathrm{g} / \mathrm{cm}^{3}$ & $0.01 \pm 0.0369$ & $0.00645 \pm 0.00159$ & $0.00559 \pm 0.00151$ \\
\hline
\end{tabular}

Note: a) differences between the observation groups No. 1 and No. 2 and the background level to Perm region of Russia are significant (p <0.05). 
Table 2. Change in immune parameters and specific sensitization in schoolchildren under industrial impact $(\mathrm{M} \pm \mathrm{m})$

\begin{tabular}{|c|c|c|c|c|}
\hline Indicator & $\begin{array}{l}\text { Observation group } \\
\text { No.1 }\end{array}$ & $\begin{array}{l}\text { Observation group } \\
\text { No.2 }\end{array}$ & $\begin{array}{l}\text { Comparison group } \\
\text { No. } 1\end{array}$ & $\begin{array}{l}\text { Comparison group } \\
\text { No. } 2\end{array}$ \\
\hline CD16+CD56+-lymphocytes, $10^{9} / \mathrm{cm}^{3}$ & $0.43 \pm 0.16$ & $0.36 \pm 0.11$ & $0.32 \pm 0.04$ & $0.39 \pm 0.075$ \\
\hline CD16+CD56+- lymphocytes, \% & $16.2 \pm 4.91$ & $17.0 \pm 6.85$ & $13.8 \pm 2.02$ & $16.8 \pm 2.887$ \\
\hline CD19+- lymphocytes, $10^{9} / \mathrm{cm}^{3}$ & $0.34 \pm 0.14$ & $0.27 \pm 0.08^{b}$ & $0.3 \pm 0.048$ & $0.397 \pm 0.068$ \\
\hline CD19+- lymphocytes, \% & $11.8 \pm 2.78$ & $11.9 \pm 2.91^{b}$ & $12.53 \pm 1.25$ & $17.47 \pm 3.51$ \\
\hline CD3+- Iymphocytes, $10 \% / \mathrm{cm}^{3}$ & $1.86 \pm 0.39$ & $1.56 \pm 0.43$ & $1.68 \pm 0.23$ & $1.39 \pm 0.30$ \\
\hline CD3+- lymphocytes, \% & $66.8 \pm 5.26$ & $67.5 \pm 6.60$ & $69.67 \pm 2.36$ & $58.47 \pm 8.15$ \\
\hline $\mathrm{CD}^{+}{ }^{+} \mathrm{CD} 4^{+}$-lymphocytes, $10^{9} / \mathrm{cm}^{3}$ & $1.05 \pm 0.29$ & $0.89 \pm 0.28$ & $0.92 \pm 0.15$ & $0.87 \pm 0.14$ \\
\hline CD3+CD4+- lymphocytes, \% & $37.3 \pm 4.56$ & $38.3 \pm 5.91$ & $37.8 \pm 2.62$ & $37.13 \pm 3.36$ \\
\hline $\mathrm{CD}^{+}{ }^{+} \mathrm{CD}^{+}{ }^{+}$-lymphocytes, $10^{9} / \mathrm{cm}^{3}$ & $0.62 \pm 0.109$ & $0.56 \pm 0.14^{\mathrm{b}}$ & $0.606 \pm 0.083$ & $0.75 \pm 0.11$ \\
\hline CD3+CD8+- lymphocytes, \% & $22.8 \pm 3.16$ & $24.3 \pm 3.2^{\mathrm{b}}$ & $25.4 \pm 2.13$ & $32.4 \pm 3.27$ \\
\hline $\mathrm{CD}^{+} / \mathrm{CD}^{+}, \mathrm{c} . \mathrm{u}$. & $1.7 \pm 0.35$ & $1.63 \pm 0.30^{\mathrm{b}}$ & $1.53 \pm 0.17$ & $1.20 \pm 0.22$ \\
\hline Absolute phagocytosis, $10 \% / \mathrm{dm}^{3}$ & $1.78 \pm 0.254$ & $2.16 \pm 0.395$ & $1.97 \pm 0.306$ & $1.99 \pm 0.198$ \\
\hline Percentage of phagocytosis, $\%$ & $49.54 \pm 3.65$ & $48.11 \pm 2.79^{\mathrm{b}}$ & $53.0 \pm 3.16$ & $54.8 \pm 2.38$ \\
\hline Phagocytic number, c.u. & $0.94 \pm 0.083$ & $0.907 \pm 0.08^{\mathrm{b}}$ & $1.03 \pm 0.094$ & $1.08 \pm 0.077$ \\
\hline Phagocytic index, c.u. & $1.89 \pm 0.058$ & $1.871 \pm 0.083$ & $1.92 \pm 0.068$ & $1.94 \pm 0.065$ \\
\hline $\lg G, g / d^{3}$ & $11.76 \pm 0.53^{a}$ & $12.67 \pm 1.09$ & $10.10 \pm 0.64$ & $11.92 \pm 0.71$ \\
\hline $\operatorname{lgM}, \mathrm{g} / \mathrm{dm}^{3}$ & $1.495 \pm 0.10^{c}$ & $1.74 \pm 0.14$ & $1.48 \pm 0.08$ & $1.60 \pm 0.13$ \\
\hline $\lg A, g / d^{3}$ & $1.47 \pm 0.13^{c}$ & $1.93 \pm 0.23^{b}$ & $1.53 \pm 0.14$ & $1.57 \pm 0.19$ \\
\hline Total lgE, ME/cm & $96.14 \pm 54.80^{c}$ & $260.29 \pm 157.26^{b}$ & $131.68 \pm 89.87$ & $98.31 \pm 51.54$ \\
\hline $\lg \mathrm{E}$ manganese specific, $\mathrm{ME} / \mathrm{cm}^{3}$ & $0.34 \pm 0.08^{a}$ & $0.3 \pm 0.13^{b}$ & $0.044 \pm 0.007$ & $0.057 \pm 0.009$ \\
\hline $\lg E$ nickel specific, $\mathrm{ME} / \mathrm{cm}^{3}$ & $0.37 \pm 0.07^{a}$ & $0.50 \pm 0.17^{b}$ & $0.044 \pm 0.009$ & $0.046 \pm 0.008$ \\
\hline $\lg \mathrm{E}$ formaldehyde specific, $\mathrm{ME} / \mathrm{cm}^{3}$ & $0.31 \pm 0.05^{a}$ & $0.35 \pm 0.12^{b}$ & $0.032 \pm 0.006$ & $0.029 \pm 0.005$ \\
\hline IgG benzene specific, c.u. & $0.32 \pm 0.06^{a}$ & $0.31 \pm 0.07^{b}$ & $0.067 \pm 0.016$ & $0.065 \pm 0.015$ \\
\hline IgG phenol specific, c.u. & $0.29 \pm 0.05^{a}$ & $0.33 \pm 0.06^{b}$ & $0.057 \pm 0.009$ & $0.048 \pm 0.01$ \\
\hline IgG lead specific, c.u. & $0.34 \pm 0.06^{a}$ & $0.37 \pm 0.08^{b}$ & $0.051 \pm 0.009$ & $0.062 \pm 0.009$ \\
\hline Interleukin-4, pg/cm ${ }^{3}$ & $1.56 \pm 0.40^{\mathrm{a}}$ & $0.97 \pm 0.50$ & $0.46 \pm 0.25$ & $0.46 \pm 0.15$ \\
\hline Interferon - gamma, $\mathrm{pg} / \mathrm{cm}^{3}$ & $2.29 \pm 0.38^{a}$ & $2.27 \pm 0.47^{b}$ & $5.08 \pm 0.79$ & $4.87 \pm 0.58$ \\
\hline Interleukin-10, pg/cm ${ }^{3}$ & $2.77 \pm 0.52^{\mathrm{c}}$ & $4.81 \pm 0.69$ & $4.17 \pm 2.19$ & $3.83 \pm 1.69$ \\
\hline
\end{tabular}

Note: a) differences between the observation group No. 1 and the indices of the comparison group No. 1 are significant $(p<0.05)$. b) the differences between the observation group No. 2 and the indices of the comparison group No. 2 are significant $(p<0.05)$. c) the differences between the observation group No. 1 and the indices of the observation group No. 2 are significant $(\mathrm{p}<0.05)$. 


\section{CONCLUSION}

The present study of the immune profile of schoolchildren living in areas with a high intensity of industrial exposure showed significant changes in both cellular and humoral components of immune reactivity (especially pronounced for middle school pupils) associated with a change in the ratio of CD4+/CD8+ lymphocytes, phagocytic activity, cytokine markers, production of serum immunoglobulins IgA and IgM and an increase in the level of specific sensitization to industrial pollutants, which can be used to solve the problems of monitoring the health status of different age groups of schoolchildren in conditions of different intensity and nature of exposure to environmental factors.

\section{REFERENCES}

[1] E.V. Anganova, L.A. Stepanenko, O.V. Kolbaseeva, M.F. Savchenko, Environment and human health, Siber. Med. J. (Irkutsk) 1 (2015) $122-125$.

[2] B.V. Zasorin, O.M. Kurmangaliev, L.S. Ermukhanova, Peculiarities of the immune status in the population of urbanized areas with a high content of heavy metals, Hyg. and sanit. 3 (2012) $17-19$.

[3] E.D. Savilov, E.V. Anganova, S.V. Ilyina, L.A. Stepanenko, Technogenic pollution of the environment and public health: analysis of the situation and forecast, Hyg. and sanit. 95(6) (2016) 507-512.

[4] V.S. Rukavishnikov, N.V. Efimova, On the problem of identifying environmentally related health disorders, Bull. of the East Siber.n Sci. Center of the Siber. Branch of the Rus. Acad. of Med. Sci. 2(2) (2012) 95-98.

[5] D.R. Boverhof, G. Ladics, B. Luebke et al., Approaches and considerations for the assessment of immunotoxicity for environmental chemicals: a workshop summary, Regul. Toxicol. Pharmacol. 68(1) (2014) 96-107.

[6] D.M. MacGillivray, T.R. Kollmann, The role of environmental factors in modulating immune responses in early life, Front. Immunol. 5 (2014) 434.

[7] J.M. Kreitinger, C.A. Beamer, D.M. Shepherd, Environmental immunology: lessons learned from exposure to a select panel of immunotoxicants, J. Immunol. 196(8) (2016) 3217-3225.
[8] L.M. Masyagutova, A.B. Bakirov, Indicators of local and systemic immunity under the influence of industrial factors, Public health and healthcare 1 (2012) 25-28.

[9] E.A. Otavina, O.V. Dolgikh, K.G. Starkova et al., Changes in immunoregulatory parameters in children exposed to strontium, Med. immunol. 20(6) (2018) 899-904.

[10] T. Suzuki, T. Hidaka, Y. Kumagai, M. Yamamoto, Environmental pollutants and the immune response, Nat. Immunol. 21(12) (2020) 1486-1495.

[11] T. Tanabe, N. Yamaguchi, M. Okuda et al., Immune system reaction against environmental pollutant, Nihon Eiseigaku Zasshi 70(2) (2015) 115-119.

[12] O.V. Dolgikh, K.G. Starkova, I.N. Alikina et al., Features of immune regulation and apoptosis in children under industrial exposure, Perm Univ. Bull., Biol. Ser. 1 (2019) 84-89.

[13] D.V. Lanin, T.M. Lebedeva, The impact of chemical factors of the environment on the functions of regulatory systems in children, Hyg. and sanit. 95(1) (2016) 94-96.

[14] N.V. Zaitseva, O.Yu. Ustinova, Risk-associated health disorders in children and adolescents: assessment, prevention, correction, Quest. of school and univ. med. and health 1 (2016) 20-25.

[15] O.A. Maklakova, Assessment of the risk of developing respiratory diseases and comorbid pathology in children under conditions of atmospheric air pollution with chemicals of technogenic origin (cohort study), Health risk anal. 2 (2019) 56-63.

[16] S.B. Petrov, I.S. Sennikov, B.A. Petrov, Influence of airborne industrial pollutants of the urban environment on the incidence of diseases of an allergic nature among children, Basic res. 10-7 (2014) 1382-1385. 